\title{
UMA ANÁLISE DA GESTÃO DE PROJETOS DE EXTENSÃO DE UMA INSTITUIÇÃO FEDERAL DE ENSINO
}

\section{Rafael Rodrigues Silva}

Doutorando em Administração pela Universidade Federal do Rio Grande do Norte -

PPGA/UFRN, Rio Grande do Norte (Brasil). Professor de Administração pelo Instituto Federal do Rio Grande do Norte - IFRN, Rio Grande do Norte (Brasil).

E-mail: rafaelrodges@ outlook.com

\section{Maria Rafaela Soares Teixeira}

Graduanda em Secretariado Executivo Bilíngue pela Universidade Federal da Paraíba - UFPB, Paraíba (Brasil).E-mail: raffaellasoares@ hotmail.com

\section{Flavia Tatiane Ribeiro de Lima Rodrigues}

Graduanda em Administração pela Universidade Federal do Rio Grande do Norte - UFRN, Rio Grande do Norte (Brasil). E-mail: flaviatrl@yahoo.com.br 


\title{
UMA ANÁLISE DA GESTÃO DE PROJETOS DE EXTENSÃO DE UMA INSTITUIÇÃO FEDERAL DE ENSINO
}

\begin{abstract}
RESUMO
Este trabalho se propõe a analisar a gestão dos projetos de extensão de uma instituição federal de ensino localizada no nordeste brasileiro. Sabe-se que gerenciar projetos é aplicar conhecimentos, habilidades, ferramentas e técnicas às atividades do projeto a fim de atender aos requisitos. Portanto, foi realizada uma pesquisa qualitativa, que detalhou os processos de gerenciamento dos projetos de extensão baseando-se nas definições do Project Management Body of Knowlegde (PMBOK). Sendo assim, esta pesquisa caracteriza-se como um estudo de caso, no qual se realizaram análises dos editais de seleção dos projetos e entrevista com o coordenador de extensão do campus. Os resultados mostraram que a instituição está em consonância com um guia que contém boas práticas de gerenciamento de projetos, o PMBOK; entretanto, existem alguns aspectos que precisam ser melhorados.
\end{abstract}

Palavras-chave: Gestão de projetos. PMBOK. Projetos de extensão.

\begin{abstract}
The purpose of this study is analyze the project management of extension projects of a federal educational institution located in northeastern Brazil. It is known that managing projects is to apply knowledge, skills, tools and techniques to project activities in order to meet the requirements. Therefore, a qualitative research, which detailed the management processes of extension projects based on the settings of the Project Management Body of Knowlegde (PMBOK) was performed. Thus, this research is characterized as a case study, which is conducted analyzes of the projects and interview selection notices with campus extension coordinator. The results showed that the institution is in line with a guide containing project management best practices, the PMBOK, however, there are some aspects that need to be improved.
\end{abstract}

Keywords: Project management. PMBOK. Extension projects. 


\section{INTRODUÇÃO}

As organizações modernas são movidas por projetos (Carvalho \& Rabechini Jr., 2011). Esses, por sua vez, são empreendimentos temporários aplicados às mais diversas áreas a fim de prover novos produtos e serviços (Project Management Institute [PMI], 2013). A partir da década de 1980 , as organizações perceberam que a utilização do gerenciamento de projetos proporciona muitas vantagens competitivas, tais como: produção de produtos melhores, prestação de serviços mais rápidos, qualidade e integração dos processos e atividades, maior controle periódico, dentre outros (Kerzner, 2009).

A gestão de projetos abrange conhecimento, habilidades, ferramentas e técnicas, aplicadas ao planejamento, organização, supervisão e controle que auxiliam na avaliação do desempenho e contribuem para o alcance do sucesso (Carvalho \& Rabechini Jr., 2011). Nesse aspecto, Veras (2014, p. 36) ressalta que o sucesso do gerenciamento de projetos pode ser medido por parâmetros como custo, prazo e qualidade e que a obtenção do sucesso deve considerar as expectativas e os objetivos das partes interessadas.

No âmbito dos Institutos Federais de Educação, Ciência e Tecnologia, os projetos estão presentes de várias maneiras: infraestrutura, expansão e interiorização da rede federal de ensino, abertura de novos cursos, em atendimento às demandas do Ministério da Educação (MEC), projetos de pesquisa e extensão etc. Os institutos, assim como as universidades, também devem ofertar e fomentar o ensino, a pesquisa e a extensão em favor do desenvolvimento local e regional na perspectiva da construção da cidadania (Pacheco, 2010).

Diante disso, os projetos de extensão possuem uma função importante para que esse desenvolvimento ocorra (Fórum, 2012). Desse modo, estudar a gestão de projetos de extensão torna-se relevante, pois requer que o gestor possua conhecimentos, técnicas e habilidades para gestão desses projetos, assim como ocorre em outras organizações (Landgraf, 1996).

Não foram encontrados registros na literatura que relacionam diretamente a gestão de projetos com projetos de extensão. Entretanto, foram verificados alguns estudos realizados envolvendo essa temática com projetos de pesquisa e desenvolvimento em 
instituições de ensino públicas e privadas e em parcerias entre instituições (Lima, Carvalho \& Kovaleski et al., 1999, Esteves \& Falcoski, 2013, Costa, Maccari, Martins \& Kniess, 2014, Terribili Filho, Nery \& Bentancor, 2015). Estudos como o de Terribili Filho e colaboradores (2015), verificaram que algumas dessas instituições de ensino se encontram numa fase ainda incipiente quanto ao gerenciamento de projetos.

Dessa forma, este trabalho tem como objetivo analisar o gerenciamento dos projetos de extensão em um Instituição Federal de Educação, Ciência e Tecnologia. A pesquisa abrangeu uma análise documental de editais de seleção de propostas e entrevistas semiestruturadas, onde foram abordados os cinco processos de gerenciamento propostos pelo Project Management Body of Knowlegde (PMBOK), do Project Management Institute (PMI). Assim, espera-se que este estudo contribua para melhoria dos processos de gestão de projetos no âmbito de uma instituição federal de ensino e colabore para a realização da missão dessas instituições.

O trabalho está estruturado em cinco partes: introdução; referencial; materiais e métodos; análise dos resultados; e considerações finais. A introdução traz uma visão geral do trabalho. No referencial são apresentados os principais conceitos relacionados à gestão de projetos e dos pilares (ensino, pesquisa e extensão) das instituições de ensino. $\mathrm{Na}$ parte de materiais e métodos é caracterizado o objeto de estudo e como ocorreu o procedimento da pesquisa. Em seguida, são apresentados e discutidos os resultados. Por fim, nas considerações finais, discorre-se sobre às contribuições, limitações, novas direções, além de ser enfatizado o alcance do objetivo proposto.

\section{REFERENCIAL TEÓRICO}

Para fundamentar a proposta central deste trabalho são abordados os principais conceitos sobre gestão de projetos e o Guia PMBOK. Quanto ao objeto estudado, são apresentadas as principais características dos Institutos Federais de Educação, Ciência e Tecnologia ressaltando sua proposta de promover o desenvolvimento regional a partir do tripé ensino, pesquisa e extensão. 


\section{Gestão de projetos}

O Guia PMBOK define o gerenciamento de projetos como a aplicação de conhecimento, habilidades, ferramentas e técnicas às atividades do projeto a fim de atender aos seus requisitos (Project Management Institute [PMI], 2008). A gestão de projetos é realizada por meio da aplicação e da integração dos seguintes processos: iniciação, planejamento, execução, monitoramento e controle, e encerramento.

Os projetos são divididos em fases e, independente da abrangência do escopo, possuem ciclos de vida parecidos. No mínimo, haverá uma fase inicial, uma fase (ou fases) intermediária(s) e uma fase final. Geralmente, o número de fases depende da complexidade e da área em que o projeto está sendo desenvolvido. Por exemplo, projetos aeroespaciais têm características distintas do que os da construção civil (Veras, 2014, Carvalho \& Rabechini Jr. 2011).

De acordo com o Guia PMBOK (PMI, 2013), o ciclo de vida do projeto define as fases que conectam o início ao seu final. A definição do ciclo de vida pode ajudar o gerente de projetos a decidir se deve tratar o estudo de viabilidade como a primeira fase ou como uma atividade independente.

A Figura 1 mostra o ciclo de vida de um projeto e as fases integrantes. Observa-se que a etapa mais longa é a intermediária onde se encontram os principais marcos e se concentra maior esforço de todas as partes envolvidas.

Figura 1. Fases do ciclo de vida do projeto.

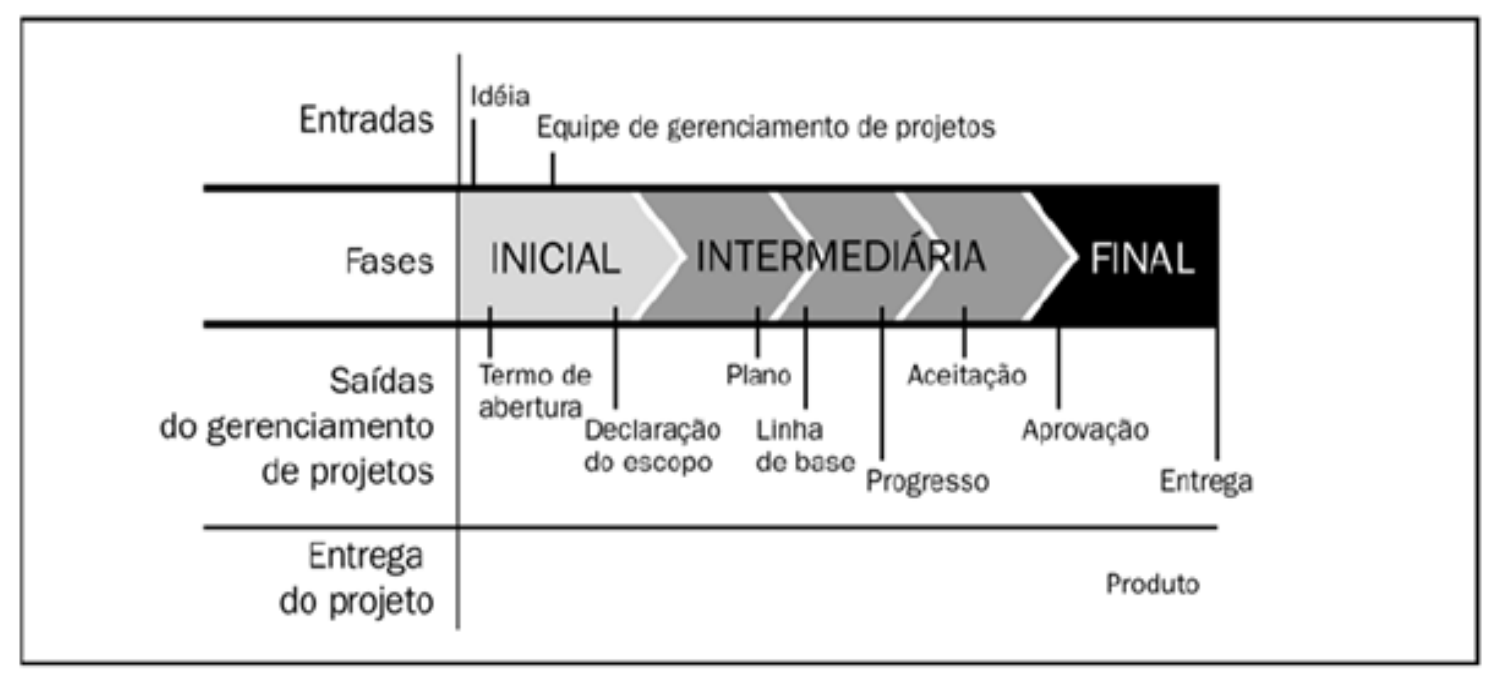

Revista de Gestão e Secretariado-GeSec, São Paulo, v. 7, n. 3, p 150-171, set./dez. 2016. 
Fonte: Project Management Institute (2008).

Os processos podem gerar informações para aprimorar o gerenciamento de projetos. Desse modo, o Quadro 1 descreve a natureza desses processos em termos de integração, suas interações e seus objetivos. Eles são agrupados em cinco categorias consideradas necessárias ao gerenciamento (PMI, 2013).

De acordo com a quinta versão do Guia PMBOK publicada em 2013, o conhecimento de gerenciamento de projetos consiste em cinco grupos de processos, 47 processos e dez áreas de conhecimento (integração, escopo, tempo, custos, qualidade, recursos humanos, comunicação, riscos, aquisição e partes interessadas). Segundo Veras (2014, p. 40), as boas práticas apresentadas no Guia evidenciam que "existe um consenso de que a correta aplicação dessas habilidades, ferramentas e técnicas podem aumentar a chance de sucesso dos projetos".

Quadro 1 -Processos de gerenciamento de projetos.

\begin{tabular}{|c|c|}
\hline PROCESSO & DESCRIÇÃO \\
\hline a) Iniciação & $\begin{array}{l}\text { Nesse processo, o escopo é definido e os recursos financeiros são planejados. } \\
\text { Também são identificadas as partes interessadas internas e externas (patrocinador, } \\
\text { cliente, gerente do projeto, equipe, dentre outros). Todas essas informações deverão } \\
\text { constar no termo de abertura do projeto. }\end{array}$ \\
\hline b) Planejamento & $\begin{array}{l}\text { Esses processos desenvolvem o plano de gerenciamento e os documentos que serão } \\
\text { usados para executar o projeto. O planejamento e a documentação são processos } \\
\text { interativos e contínuos e se houver mudanças haverá necessidade de revisá-los. Nesse } \\
\text { processo são explorados todos os aspectos de escopo, tempo, custos, qualidade, } \\
\text { comunicação, risco e aquisições. }\end{array}$ \\
\hline c) Execução & $\begin{array}{l}\text { Consiste nos processos realizados para concluir o trabalho definido no plano de } \\
\text { gerenciamento do projeto para cumprir suas especificações. }\end{array}$ \\
\hline $\begin{array}{l}\text { d) Monitoramento e } \\
\text { controle }\end{array}$ & $\begin{array}{l}\text { Nesse grupo de processos é verificado o desempenho do projeto e observado e } \\
\text { mensurado de forma periódica e uniforme para identificar variações em relação ao } \\
\text { plano de gerenciamento do projeto. }\end{array}$ \\
\hline e) Encerramento & $\begin{array}{l}\text { Consiste no processo de finalizar todas as atividades, visando completar formalmente } \\
\text { o projeto ou fase ou obrigação contratuais; verifica todos os processos definidos } \\
\text { quando concluído. }\end{array}$ \\
\hline
\end{tabular}

Nota Fonte: Adaptado de Project Management Institute (2013).

A literatura apresenta alguns estudos que abordam a contribuição das boas práticas para o sucesso dos projetos. No intuito de verificar a utilização e a 
disseminação das práticas de gestão de projetos, Papke-Shields, Beise e Quan (2010), a partir da análise de 52 "boas práticas" baseadas no PMBOK, com 142 membros do PMI, observaram que as áreas utilizadas com mais frequência são o gerenciamento do tempo, escopo e custo, também conhecido como o "tripé de ferro" da gestão de projetos. Para examinar o uso dessas práticas os autores classificaram-nas por nível de uso relativo, dividindo-as em três grupos de uso relativo: baixo (até 3,5); moderado (de 3,5 a 4,0); alto (superior a 4,0), conforme Figura 2.

Figura 2. Uso relativo de práticas de gestão de projetos por área do PMBOK.

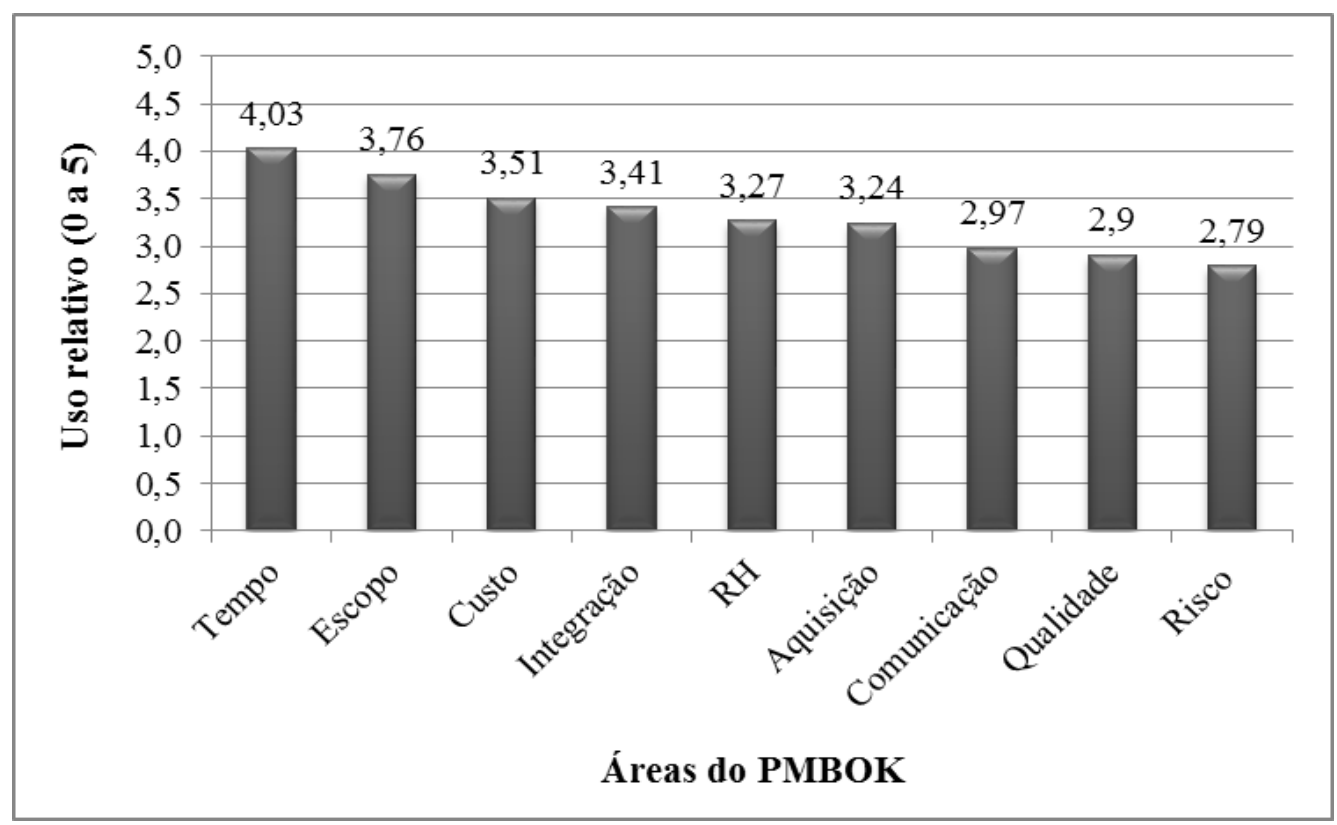

Fonte: Adaptado de Papke-Shields, K. E., Beise, C., \& Quan, J. (2010).

A pesquisa de Papke-Shields e colaboradores também revelou que há diferenças no uso das práticas, dependendo do contexto dos projetos, em função dos custos, da duração e da quantidade de pessoas envolvidas; mas que o uso de diferentes práticas não depende do tipo de indústria ou do tamanho da organização.

Em outra pesquisa abrangendo o Guia PMBOK, Bomfin, Nunes e Hastenreiter (2012) verificaram que saber planejar, estudar e alocar recursos necessários nos projetos podem aumentar as chances de sucesso. Os resultados mostraram que o conhecimento das boas práticas minimiza as incertezas e podem ajudar na obtenção do sucesso do projeto, apesar de não o garantir.

Revista de Gestão e Secretariado-GeSec, São Paulo, v. 7, n. 3, p 150-171, set./dez. 2016. 
Desse modo, a literatura mostra que utilização das boas práticas é um fator preponderante para que um projeto obtenha sucesso. Além disso, é preciso atentar para outros aspectos organizacionais que contribuem para aumentar a frequência com que os projetos alcançam o sucesso, tais como: informatização, processos internos, relações interpessoais, alinhamento estratégico dentre outros (Carvalho \& Rabechini Jr., 2011).

Nesse sentido, faz-se necessário trabalhar a gestão de projetos dentro de instituições de ensino e como as boas práticas podem ser exploradas dentro dos contextos do ensino, da pesquisa e extensão considerando que existe uma indissociabilidade entre esses três pilares.

\section{Os pilares ensino, pesquisa e extensão e os institutos federais}

Segundo o artigo 207 da Constituição Federal, "as universidades gozam de autonomia didático-científica, administrativa e de gestão financeira e patrimonial, e obedecerão ao princípio de indissociabilidade entre ensino, pesquisa e extensão" (Constituição, 1988). Desse modo, é dever das universidades promover pesquisa e a extensão consoante ao ensino.

No âmbito dos Institutos Federais de Educação, Ciência e Tecnologia, essa prerrogativa também é observada na lei de criação dos Institutos Federais, Lei 11.892 de 29 de novembro de 2008. De acordo com a Lei, os Institutos devem adotar como diretriz "a necessidade de atuar no ensino, na pesquisa e na extensão, compreendendo as especificidades dessas dimensões $\mathrm{e}$ as inter-relações que caracterizam sua indissociabilidade" (Silva, Vidor, Pacheco \& Pereira, 2009, p. 9).

Quanto ao pilar extensão, em particular, deve pautar-se sob o princípio constitucional da indissociabilidade entre ensino, pesquisa e extensão, sendo um processo interdisciplinar, educativo, cultural e científico que visa a promoção e a interação transformadora entre Universidade e outros setores da sociedade (Fórum, 2012). No âmbito da extensão profissional científica e tecnológica promovida pelos Institutos Federais, caracteriza-se como

Processo educativo, cultural, social, científico e tecnológico que promove a interação entre as instituições, os segmentos sociais e o mundo do trabalho com ênfase na produção, desenvolvimento e difusão de conhecimentos científicos e tecnológicos 
visando o desenvolvimento socioeconômico sustentável local e regional (Conif, 2013, p. 16).

Dessa forma, os projetos de extensão podem atuar em algumas dimensões operativas que transversalizam as áreas do conhecimento e os eixos tecnológicos dessas instituições, a saber: desenvolvimento tecnológico; projetos sociais; estágio e emprego; cursos de extensão ou formação inicial e continuada; projetos culturais, artísticos, científicos, tecnológicos e esportivos; visitas técnicas; empreendedorismo e associativismo; e acompanhamento de egressos (Conif, 2013).

Segundo Landgraf (1996), a maior dificuldade do gerenciamento desse tipo de projeto (pesquisa e extensão) é que costuma ser feito por pessoas despreparadas. Geralmente, o gestor de um projeto de extensão é um técnico administrativo ou professor especialista no tema. Entretanto, seu treinamento gerencial costuma ser mínimo e sua formação em gestão de projetos foi construída informalmente, eventualmente guiada pelo orientador de mestrado ou doutorado (Landgraf, 1996). Lima et al. (1999) acrescentam que a oferta e disponibilidade de literatura e treinamento especificamente para a gestão de projetos de pesquisa e desenvolvimento em Instituições de Ensino ainda não são significativas.

Em um estudo recente, Terribili Filho e colaboradores (2015), realizaram uma pesquisa exploratória acerca das práticas de gerenciamento de projetos em instituições de ensino da cidade de São Paulo e verificaram que o gerenciamento de projetos nessas instituições ainda está em uma fase embrionária (inicial). Os principais problemas encontrados foram: inexistência clara do patrocinador, ausência de procedimentos padronizados, mudanças de escopo sem aprovação prévia, cronogramas não atualizados periodicamente, projetos não monitorados por indicadores durante sua execução, os gerentes não têm treinamento específico ou prática em gestão de projetos e não existe do plano de comunicação.

Portanto, apesar da disparidade entre as datas das publicações desses autores, verifica-se que os resultados da pesquisa de Terribili et al. (2015) ainda corroboram com o que foi observado por Landgraf (1996) e Lima et al. (1999) em meados da década de 1990.

Dessa maneira, torna-se relevante trabalhar essas duas temáticas, considerando a abrangência e os aspectos dos projetos de extensão e que esses possuem características peculiares envolvendo vários stakeholders e precisam ser conduzidos com o mesmo 
rigor profissional como outros projetos de áreas que adotam metodologias de gerenciamento de projetos.

\section{METODOLOGIA}

A pesquisa foi aplicada em um Instituto Federal de Educação, Ciência e Tecnologia. Assim, a caracterização da instituição pesquisada é descrita na próxima seção e seguida do planejamento e método da pesquisa.

\section{Caracterização do objeto de estudo}

A instituição federal de ensino pesquisada situa-se na região Nordeste e tem como função social ofertar educação profissional e tecnológica, de qualidade referenciada socialmente e de arquitetura político-pedagógica capaz de articular ciência, cultura, trabalho e tecnologia, comprometida com a formação humana integral, com o exercício da cidadania e com a produção e a socialização do conhecimento, visando, sobretudo, a transformação da realidade na perspectiva da igualdade e da justiça social (Silva et al., 2009).

De acordo com o Ministério da Educação (MEC), sabe-se que a concepção da Educação Profissional e Tecnológica orienta os processos de formação com base nas premissas da integração e da articulação entre ciência, tecnologia, cultura e conhecimentos específicos e do desenvolvimento da capacidade de investigação científica como dimensões essenciais à manutenção da autonomia e dos saberes necessários ao permanente exercício da laboralidade, que se traduzem nas ações de ensino, pesquisa e extensão (Ministério da Educação [MEC], 2010).

No âmbito da extensão, a Instituto tem por objetivo executar projetos que configurem um processo educativo, científico, artístico-cultural e desportivo que se articulam ao ensino e à pesquisa, com o fim de intensificar uma relação transformadora entre a instituição e a sociedade.

A Pró-reitoria de Extensão (Proex) é um conjunto articulado de projetos e de ações processuais de caráter educativo, social, cultural científico ou tecnológico, de 
caráter orgânico-institucional, com clareza de diretrizes e orientadas para um objetivo especifico com prazo determinado sendo executado a médio e longo prazo.

Em cada campus existe uma Coordenação de Extensão (Coex). A Coex do campus de Nova Cruz atua há dois anos e meio e, desde sua criação, já monitorou oito projetos de extensão, todos aprovados mediante editais da Proex.

A Figura 3 apresenta de forma generalista como está estruturada a coordenação de extensão na instituição.

Figura 3. Disposição da coordenação de extensão dentro da instituição de ensino.

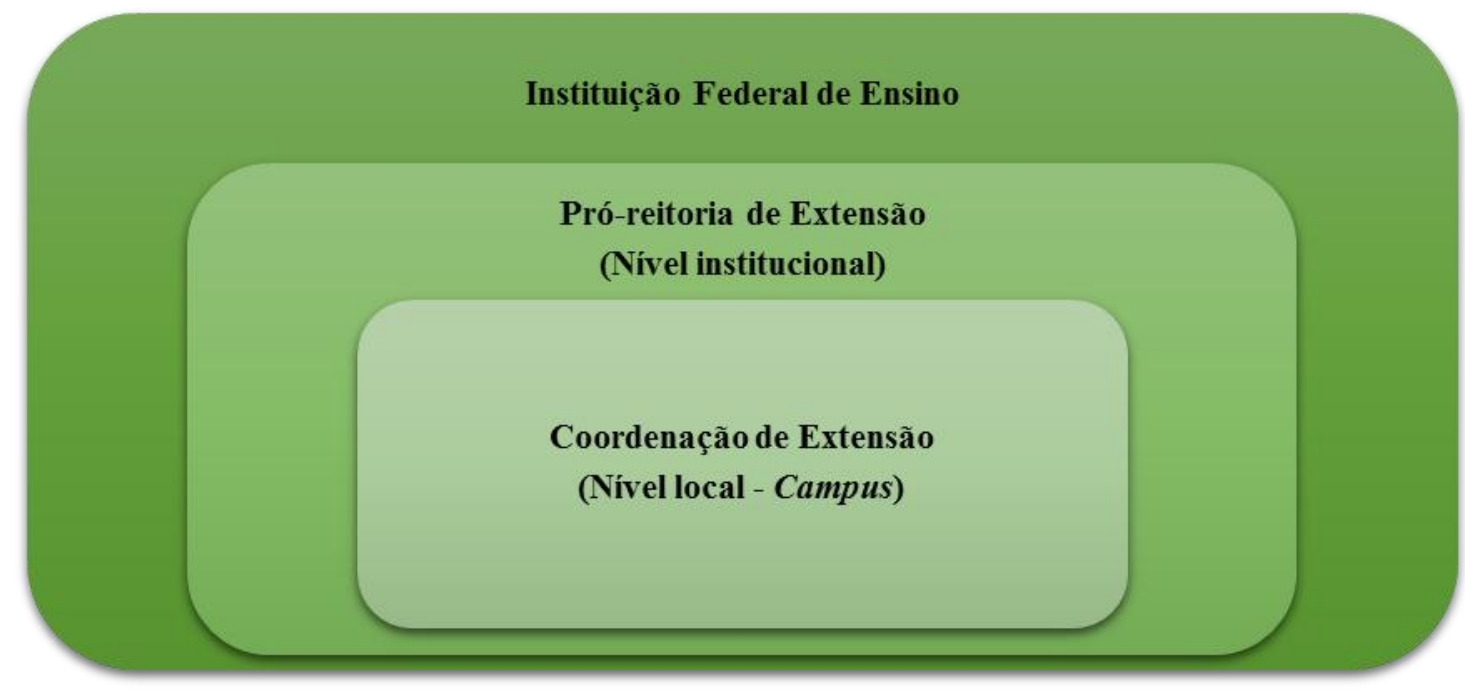

Fonte: Elaboração própria.

No período de realização da pesquisa havia três projetos aprovados via edital e mais três em fase de aprovação. Os projetos aprovados estão relacionados com ensino de Matemática, condução e coordenação de grupos em ambientes educativos e qualidade de vida.

\section{Planejamento e método da pesquisa}

A partir da definição do tipo de pesquisa, pode-se discutir qual estratégia de pesquisa a ser adotada (Yin, 2005). Dessa forma, seguindo os critérios propostos por Yin (2005), adotou-se o estudo de caso como estratégia de pesquisa, considerando que esta pesquisa está circunscrita a uma instituição, que visa responder questões do tipo "como" e "por que", em que não há controle dos eventos e está focada em eventos 
contemporâneos. Quanto às análises, possui uma abordagem qualitativa baseada em entrevistas e análise documental. Nesse caso, este trabalho visa obter uma compreensão qualitativa dos processos de gestão dos projetos de extensão (Malhotra, 2005).

Quanto aos procedimentos de coleta dos dados, foram realizadas entrevistas estruturadas com o auxílio de um questionário previamente estabelecido com questões abertas (Marconi \& Lakatos, 2010). Também foi realizada uma análise de editais de seleção de projetos de extensão.

No tocante à entrevista, foi elaborado um questionário com 18 perguntas abertas baseado nos cinco processos de gerenciamento do Guia PMBOK: iniciação, planejamento, execução, monitoramento e controle, e encerramento. O Quadro 2 apresenta a estrutura do questionário e descreve os principais aspectos do PMBOK que nortearam cada pergunta.

Quadro 2 -Estrutura do questionário.

\begin{tabular}{|c|c|c|}
\hline Processos & $\begin{array}{l}\text { Quantidade de } \\
\text { questões }\end{array}$ & Aspectos do Guia PMBOK abordados \\
\hline Iniciação & 3 & $\begin{array}{l}\text { - termo de abertura do projeto; } \\
\text { - partes interessadas (stakeholders); } \\
\text { - suporte institucional para planejamento. }\end{array}$ \\
\hline Planejamento & 5 & $\begin{array}{l}\text { - plano de gerenciamento do projeto; } \\
\text { - plano de gerenciamento do escopo; } \\
\text { - elaboração da estrutura analítica do projeto (EAP); } \\
\text { - plano de monitoramento e controle; } \\
\text { - plano de comunicação. }\end{array}$ \\
\hline Execução & 4 & $\begin{array}{l}\text { - operacionalização do projeto; } \\
\text { - gestão da equipe (recursos humanos); } \\
\text { - gestão da comunicação e informações; } \\
\text { - gerenciamento das partes interessadas. }\end{array}$ \\
\hline $\begin{array}{l}\text { Monitoramento e } \\
\text { Controle }\end{array}$ & 4 & $\begin{array}{l}\text { - monitoramento e controle do projeto; } \\
\text { - monitoramento e controle do escopo; } \\
\text { - controle do cronograma; } \\
\text { - comunicação com as partes interessadas. }\end{array}$ \\
\hline Encerramento & 2 & $\begin{array}{l}\text { - termo de encerramento do projeto; } \\
\text { - processos de encerramento. }\end{array}$ \\
\hline Total de questões & 18 & \\
\hline
\end{tabular}

Nota Fonte: Elaboração própria a partir do Project Management Institute (2013).

Revista de Gestão e Secretariado-GeSec, São Paulo, v. 7, n. 3, p 150-171, set./dez. 2016. 
Segundo Malhotra (2005, p. 236), a vantagem do uso de perguntas abertas é que "permitem que o entrevistado expresse suas atitudes e opiniões sem a tendenciosidade associada a respostas restritas às alternativas predeterminadas”.

As entrevistas foram realizadas pessoalmente nos dias 29 e 30 de março de 2016 com dois coordenadores de extensão (Coex) de dois campi distintos do Instituto. Ressalta-se que os coordenadores atuam há mais de dois anos como coordenadores de extensão. Na ocasião, as entrevistas foram gravadas em áudio com duração média de 45 minutos (cada) e transcritas com o auxílio do MS-Office Word 2013 e analisadas com o auxílio do MS-Office Excel 2013.

A outra estratégia utilizada para coleta de dados foi a análise documental em que foram analisados três editais de seleção de projetos, todos publicados pela Proex da instituição no ano de 2015. Como os editais sugerem, em dois itens específicos, procedimentos para planejamento e controle dos projetos, tornou-se relevante sua análise para identificação de práticas de gestão aderentes ao PMBOK.

Para análise documental, foi utilizado como roteiro um quadro dos processos do Guia PMBOK (PMI, 2013, p. 60) que descreve de forma geral todos os processos que a gestão de um projeto deve contemplar.

\section{ANÁLISE E DISCUSSÃO DOS RESULTADOS}

Doravante, o trabalho dedica-se a apresentar os resultados da pesquisa, provenientes das entrevistas e das análises dos editais. Em seguida, são apresentadas algumas sugestões de melhoria para os processos de gestão de projetos da instituição da Instituição.

\section{Análise documental}

Os editais têm o objetivo de selecionar propostas, que estejam inseridas na modalidade de projetos de extensão/pesquisa aplicada. Os editais estão estruturados nos seguintes tópicos: introdução, objetivo, definições, linhas temáticas, cronograma, recursos orçamentários e financeiros, a definição de limites selecionados por campus, as 
condições de participação do servidor e do aluno, itens financiáveis, análise e julgamento das propostas, os critérios para desempate das propostas selecionadas, acompanhamento e monitoramento, divulgação de resultados e casos omissos.

Dessa forma, são pré-selecionadas as propostas submetidas dentro do prazo de inscrição estipulado e devidamente cadastradas em um sistema on-line chamado SUAP, no módulo "Projetos de Extensão". A pré-seleção é realizada pelo coordenador do campus (Coex) e enviada à Proex para validação final. Os critérios a serem observados para a pré-seleção das propostas são os exigidos nos editais.

Quanto aos processos de gerenciamento de projetos sugeridos pelo PMBOK foram verificados nos editais alguns aspectos que são aderentes às boas práticas desse Guia.

No item de "análise e julgamento da proposta" são observados alguns elementos (pré-requisitos) obrigatórios que estão em consonância com o PMBOK. O atendimento a esses requisitos são essenciais para que o projeto passe para fase de aprovação. Os pré-requisitos são: impactos sociais na comunidade; adequação do plano de aplicação e do cronograma de desembolso; e divulgação dos resultados do projeto.

Quanto aos impactos sociais na comunidade, o texto do edital faz menção a uma das principais partes interessadas dos projetos de extensão, a comunidade, devendo ser colocadas as expectativas do coordenador sobre os resultados que poderão ser gerados para a comunidade beneficiada. Observa-se que este aspecto é aderente aos processos de identificação (processo de iniciação) e planejamento das partes interessadas (processo de planejamento) propostas pelo PMBOK (PMI, 2013). Além disso, corrobora com a ideia de Veras (2014), em considerar o sucesso do projeto o atendimento aos objetivos das partes interessadas.

Em relação à adequação do plano de aplicação e do cronograma de desembolso, observa-se o alinhamento com o processo de estimar os recursos das atividades da fase de planejamento do PMBOK. No edital pede que seja feito um plano que deve apresentar um cronograma dos gastos necessários à execução das atividades propostas e detalhamento das despesas.

De maneira geral, a divulgação dos resultados do projeto está em consonância com o processo de encerramento. O coordenador deve antever, pois, as possíveis produções que poderão ser realizadas como fruto das atividades desenvolvidas, tais 
como apresentações em congressos, produção de livros, artigos, seminários, oficinas e outras produções acadêmicas. No caso dos projetos de extensão, é importante que os resultados sejam divulgados como uma forma de prestar contas à sociedade e de apresentar os principais avanços em determinada área, além de ser uma oportunidade para falar de boas práticas realizadas e das lições aprendidas.

Outro item dos editais que mostra aderência aos processos propostos pelo PMBOK é o "monitoramento e controle". Essa parte versa sobre como deve ser realizado o acompanhamento dos projetos por parte da Proex e dos coordenadores. Em linhas gerais, o acompanhamento deve ser realizado pelo sistema SUAP, em que os coordenadores de projeto devem informar o progresso periodicamente a ser validado pela Coex para liberação de pagamentos. Dessa maneira, esse procedimento reflete processos de monitoramento e controle propostos pelo PMBOK (PMI, 2013), tais como: monitorar o trabalho do projeto, controlar o trabalho e os custos.

A análise dos editais mostra que existe certo nível de aderência dos processos de gestão de projetos de extensão aos processos do Guia PMBOK (PMI, 2013). Entretanto, observa-se que o edital não contempla alguns aspectos que poderiam ser exigidos como pré-requisito para melhorar a gestão, tais como o termo de abertura e o plano de gerenciamento do projeto. Portanto, para promover complementariedade às análises dos editais, em seguida são apresentados os resultados das entrevistas realizadas com os coordenadores de Coex.

\section{Análise da entrevista}

As entrevistas foram realizadas com dois coordenadores de Coex de dois campi distintos do Instituto a partir de um roteiro composto por 18 questões abertas, com base nos 47 processos do PMBOK (PMI, 2013). As questões foram elaboradas de acordo com análise dos editais de extensão, de modo que foram simplificadas e adequadas ao que era necessário para fazer a gestão. Sendo assim, foram obtidos os resultados a seguir. 


\section{Iniciação}

$\mathrm{Na}$ fase de iniciação foi visto que a Instituição dispõe de um sistema, o SUAP, para realização de planejamento e controle, e os documentos que formalizam as características do projeto são feitos nesse sistema com base no que foi descrito no edital de seleção.

De acordo com os entrevistados, é preciso inserir no sistema SUAP algumas informações básicas, tais como: objetivos, metas, cronograma, resultados esperados etc. Entretanto, não está claramente identificado um documento que se caracterize como um termo de abertura do projeto, que contenha: finalidade ou justificativa, objetivos mensuráveis e critérios de sucesso relacionados; requisitos de alto nível, premissas e restrições, riscos, resumo do cronograma de marcos, resumo do orçamento, lista das partes interessadas, requisitos para aprovação, gerente do projeto, nível de autoridade designados, e nome e autoridade do patrocinador (PMI, 2013).

A identificação das partes interessadas é realizada no sistema, conforme previsto no edital. É necessário que sejam descritas as principais partes envolvidas, em especial a comunidade ou grupo de pessoas, que serão beneficiadas com o projeto. Entretanto, esse aspecto é colocado apenas na perspectiva do coordenador, enquanto que o Guia PMBOK (PMI, 2013) sugere que o registro das partes interessadas deve refletir os principais requisitos e expectativas que as partes interessadas possam ter em relação ao projeto.

Em relação ao suporte institucional para o planejamento, os entrevistados relataram que o próprio sistema SUAP possui uma área para monitoramento e controle do andamento do projeto. De acordo com os entrevistados, o cronograma é atualizado pelo coordenador e acompanhado pela Coex.

\section{Planejamento}

$\mathrm{Na}$ fase de planejamento, o documento que define as diretrizes de gerenciamento do projeto é elaborado no próprio SUAP, pois nele há um roteiro para tal. Contudo, no sistema não há uma declaração do escopo que, segundo o PMBOK (PMI, 2013), é um 
requisito fundamental para os projetos, mas segundo os entrevistados, a estrutura do SUAP deixa implícito que existe uma definição de escopo do projeto.

No SUAP é exigida a inserção de uma sequência de atividades; por exemplo, para cada meta do projeto são feitas as seguintes perguntas: como fazer, em quanto tempo e quais recursos são necessários. Porém, não é solicitada explicitamente a definição de um cronograma. Dessa forma, observa-se forte aderência aos processos de gerenciamento do tempo do projeto, tais como: definir as atividades, estimar recursos das atividades, estimar as durações e desenvolver o cronograma (PMI, 2013).

O proponente do projeto pode cadastrar quantas metas desejar. E para cada meta pode ser cadastrada quantas atividades forem necessárias. Nesse caso, há a possibilidade de o proponente cadastrar um cronograma das atividades bem elaborado.

Existe uma definição de parâmetros de controle a ser verificado ao longo da execução do projeto que indica uma forma qualitativa e uma quantitativa para monitoramento. $\mathrm{O}$ controle é feito tanto pelo próprio coordenador do projeto quanto pelo coordenador de extensão do campus. Nesse aspecto, ficou claro que o coordenador de extensão é responsável pelo processo de monitoramento e controle do trabalho, assim como é sugerido pelo PMBOK (PMI, 2013).

A comunicação entre as partes envolvidas é de responsabilidade do coordenador sendo realizada de acordo a necessidade de comunicação de cada projeto. Quanto à comunicação, não existe um plano de gerenciamento definido, cada coordenador faz da forma como bem entender.

\section{Execução}

$\mathrm{Na}$ execução, a operacionalização do projeto deve ser feita de acordo com o que foi planejado mês a mês. O gerenciamento das atividades e equipe é feito pelo coordenador do projeto e a Coex monitora o projeto pelo sistema após o registro da execução de cada atividade.

A distribuição de informações entre as partes interessadas também é realizada de acordo com cada coordenador de projeto e pode ser feita pelo site, por convites ou pessoalmente. 
Segundo os entrevistados, geralmente, não são verificadas as expectativas das partes interessadas, pois os projetos de extensão só são divulgados após aprovação. Entretanto, é importante que sejam informados os resultados esperados, como uma prévia das contribuições que o projeto poderá proporcionar.

Assim, os processos de execução estão ligados diretamente à realização das tarefas e à gestão da equipe, garantia da qualidade e gestão das comunicações e das partes interessadas (PMI, 2013). No caso do Instituto, fica a cargo do coordenador do projeto realizar essas atividades o que, nesse caso, reflete o conhecimento e a experiência de cada coordenador. Portanto, corrobora com o que Landgraf (1996) e Lima et al. (1999) já observaram sobre a necessidade de capacitação de gestores desse tipo de projeto.

\section{Monitoramento e controle}

O acompanhamento e a verificação do escopo são realizados pelos registros que são feitos no SUAP. De forma geral, o monitoramento e o controle são feitos pelas informações inseridas no sistema que são validadas pelo coordenador de extensão do campus e repassadas para Proex.

Além disso, o desempenho do projeto pode ser informado às demais partes por meio de redes sociais e a partir do seu próprio relatório.

De modo geral, o processo de monitoramento e controle é simples; entretanto observou-se que o coordenador do projeto tem papel importante nesse processo, ressaltando ainda mais a necessidade de formação na área.

\section{Encerramento}

Quanto ao encerramento, o documento que formaliza o encerramento está no SUAP. Após o preenchimento, o coordenador da extensão deve validar o encerramento no sistema. Entretanto, não existe um documento que registre as lições aprendidas do projeto e que seja compartilhado com os demais coordenadores e pesquisadores. 
Dessa forma, existe um processo que encerra formalmente o projeto, conforme aborda o PMBOK (PMI, 2013) na área inerente à integração do projeto. É nessa etapa que é verificado o alcance dos objetivos e se as entregas serão aceitas ou não.

Em uma análise conjunta, observa-se que os processos atuais são aderentes às boas práticas do Guia PMBOK. Entretanto vários aspectos podem ser melhorados para que a gestão e, consequentemente, os resultados dos projetos sejam melhores e maiores.

Nesse sentido, sugere-se que poderia ser implantados no SUAP uma definição de escopo e uma ferramenta para elaboração do cronograma, pois é importante que essas fases sejam claras, por estarem relacionadas ao planejamento do projeto. Isso permitirá melhor acompanhamento e a verificação do escopo e do cronograma, visto que facilitará o monitoramento do projeto e a verificação se a execução está conforme o planejado. Caso não esteja, procurar atualizar o seu processo e gerenciar mudanças.

Melhorar a comunicação com alunos e servidores, comunicando os projetos não só na página na internet, mas nas salas de aula, de forma a despertar o interesse de todos.

Estabelecer uma forma eficiente de comunicação entre os coordenadores de projetos e as partes envolvidas que são alunos ou servidores.

Também recomenda-se estabelecer um método para a verificação das expectativas das partes interessadas, pois assim se pode obter um feedback e saber se o projeto realmente atenderá uma demanda identificada, o que pode ser utilizado até como critério de seleção das propostas.

Inserir no sistema um resumo sobre as lições aprendidas nos projetos e que possa ser compartilhado com todos da instituição para melhoria nos processos de gestão de projetos e no desenvolvimento de novos.

Estimular o envolvimento dos alunos em projetos de pesquisa e extensão, buscando realizar eventos com integração de cultura de projetos desse tipo.

Selecionar os melhores trabalhos com premiações e menções honrosas e, desse modo, proporcionar um espaço para troca de experiências e lições aprendidas. 


\section{CONSIDERAÇÕES FINAIS}

Os projetos de extensão são criados com grandes áreas temáticas estabelecidas segundo prioridades sociais e com elementos de sistematização de ações extensionistas para que sejam indicadas para o planejamento e com intervenções transformadoras. Portanto, é por meio dessas ações extensionistas envolvendo professores, estudantes e técnicos que a instituição interage com a sociedade em um exercício de contribuição mútua (Fórum, 2012).

Foram encontrados muitos pontos positivos na instituição analisada, os quais foram estudados a partir das diretrizes do PMBOK para que um projeto seja bem executado. Desse modo, pode-se dizer que a ferramenta de acompanhamento de projetos da instituição analisada está em consonância com um guia que contém as melhores práticas e as mais utilizadas no mundo dos projetos.

Visto que a literatura indica uma necessidade de melhoria da gestão desse tipo de projeto e a capacitação de seus gestores (Terribili Filho et al. 2015, Lima et al., 1999, Landgraf, 1996), os resultados aqui apresentados também indicaram essa necessidade de melhoria nos processos de gerenciamento de projetos. E, apesar de o sistema utilizado pelo Instituto mostrar aderência ao Guia do PMI (2013), ainda podem ser feitos muitos avanços nesse sentido.

Dentre os principais processos verificados no Instituto destacaram-se os grupos de processos de planejamento e de monitoramento e controle. E, entre as dez áreas de conhecimento abordadas pelo Guia PMBOK, verificou-se forte aderência ao gerenciamento do tempo e dos recursos humanos e financeiros do projeto.

Os procedimentos de pesquisa compreenderam a realização de análise documental e entrevistas com coordenadores de extensão do Instituto. As escolhas por esses procedimentos, bem como a utilização do estudo de caso como estratégia de pesquisa, mostraram-se adequados para o alcance dos objetivos propostos.

Quanto ao processo de pesquisa, não houve grandes dificuldades para sua realização. Um fator que contribuiu foi a existência de um sistema para acompanhamento de projetos, pois assegura que os recursos disponíveis sejam alocados da maneira eficiente e permite aos coordenadores do projeto perceber "o que está acontecendo" e "para onde as coisas estão indo" dentro da instituição. 
Esta pesquisa limitou-se à análise dos processos de gerenciamento de projetos de extensão, a partir de editais e de entrevistas com coordenadores. Desse modo, sugere-se como continuação deste trabalho, a realização de estudo mais amplo envolvendo aspectos sobre maturidade organizacional em gerenciamento de projetos no intuito de verificar o quão o Instituto está apto em gerenciar projetos. Essa análise mais ampla pode proporcionar melhorias em várias áreas que não só às ligadas aos projetos de extensão.

\section{REFERÊNCIAS}

Bomfin, D. F. ; Nunes, P. C. A. \& Hastenreiter, F. (2012). Gerenciamento de projetos segundo o guia PMBOK: desafios para os gestores. Revista Gestão e Projetos. 3(3), 58-87.

Carvalho, M. M. \& Rabechini Jr., R. (2011). Fundamentos em gestão de projetos: construindo competências para gerenciar projetos (3a ed.). São Paulo: Atlas.

Conselho Nacional das Instituições Federais de Educação profissional e Tecnológica - Conif (2013). Extensão Tecnológica - Rede Federal de Educação Profissional, Científica e Tecnológica / Conselho Nacional das Instituições Federais de Educação Profissional, Científica e Tecnológica. Cuiabá (MT): Conif/IFMT. Recuperado em 10 abril, 2016, de http://www.ifms.edu.br/wp-content/uploads/2013/06/documento_ extensao_tecnologica_conif.pdf.

Constituição da República Federativa do Brasil de 1988. Brasília. Recuperado em 10 abril, 2016, de http://www.planalto.gov.br/ccivil_03/Constituicao/Constituicao.htm.

Costa, G., Maccari; E. A., Martins, C. B. \& Kniess, C. T. (2014). Project Management in Higher Education Institutions: Pro-Administration Case. In: BBR Conference, 2014, Vitoria. 2th BBR Conference. Vitoria: Fucape, vol. 1. pp. 1-17.

Esteves, J. \& Falcoski, L. (2013). Gestão do processo de projetos em universidades públicas: estudos de caso. Gestão \& Tecnologia de Projetos, 8(2), 67-87.

Fórum de Pró-reitores de Extensão das Universidades Públicas Brasileiras (Forproex) (2012). Política Nacional da Extensão Universitária. Brasília, MEC/SESu; Manaus/AM, maio, 2012. Recuperado em 10 abril, 2016, de http://www.renex.org.br/documentos/2012-07-13-Politica-Nacional-de-Extensao.pdf.

Kerzner, H. (2009). Project management: a systems approach to planning, scheduling, and controlling (10a. ed.). New Jersey: John Wiley \& Sons. 
Landgraf, F. J. G. (1996). Gerenciamento de Projetos de P\&D via uso de metas técnicas quantitativas. XIX Simpósio de Gestão da Inovação da Tecnologia, São Paulo, 1996.

Lima, I. A.; Carvalho, H. G. \& Kovaleski, J. L. (1999). Gestão de projetos de pesquisa e desenvolvimento no âmbito da cooperação escola-empresa. Encontro da Associação Nacional dos Programas de Pós-graduação em Administração (EnANPAD). Recuperado em 10 de abril, 2016, de http://www.anpad.org.br/admin/pdf/enanpad1999act-11.pdf.

Malhotra, N. K. (2005). Introdução à pesquisa de marketing. São Paulo: Pearson Prentice Hall.

Marconi, M. A. \& Lakatos, E. M. (2010). Fundamentos de metodologia científica (7a ed.). São Paulo: Atlas.

Ministério da Educação (2010). Um novo modelo em educação profissional e tecnológica: concepção e diretrizes. Recuperado em 20 março, 2015, de http://portal.mec.gov.br/index.php?option=com_content\&view=article\&id=286\&Itemid $=353$.

Pacheco, E. (2010). Os institutos federais: uma revolução na educação profissional e tecnológica. Brasília: MEC/Setec.

Papke-Shields, K. E.; Beise, C. \& Quan, J. (2010). Do project managers practice what they preach, and does it matter to project success? International Journal of Project Management, 28 (7), 650-662.

Project Management Institute (2008). Um guia do conjunto de conhecimento em gerenciamento de projetos (Guia PMBOK®) (4a ed.). Project Management Institute, Four Campos Boulevard, Newton Square.

Project Management Institute (2013). Um guia do conjunto de conhecimento em gerenciamento de projetos (Guia PMBOK®. (5a. ed.). Project Management Institute, Four Campos Boulevard, Newton Square.

Silva, C. J. R.; Vidor, A. M.; Pacheco, E. M. \& Pereira, L. A. C. (2009). Institutos Federais Lei 11.982, de 29/12/2008: comentários e reflexões. Natal: Editora do IFRN.

Terribili Filho, A.; Nery, A. C. B. \& Bentancor, A. L. (2015). Gestión de proyectos de innovación en las instituciones educativas privadas en San Pablo. Revista de Estudios y Experiencias en Educación, 14 (27), dez, 85-103.

Veras, M. (2014). Gerenciamento de projetos: Project Model Canvas (PMC). Rio de Janeiro: Brasport.

Yin, R. K. (2005). Estudo de caso: planejamento e métodos (3a ed.). Porto Alegre: Bookman. 